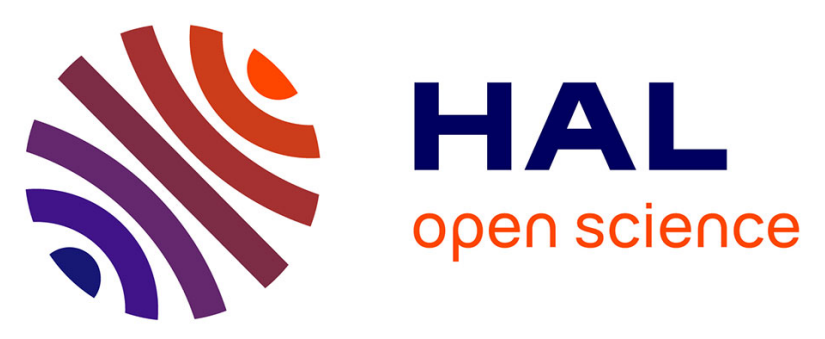

\title{
Shear Bond Strength of Self-Etching Adhesive Systems to Er:YAG Laser-Prepared Dentine with and without Pulpal Pressure Simulation
}

Nathalie Brulat, Eric Leforestier, Jean-Paul Rocca, Evelyne Darque-Ceretti, Marie-France Bertrand

\section{To cite this version:}

Nathalie Brulat, Eric Leforestier, Jean-Paul Rocca, Evelyne Darque-Ceretti, Marie-France Bertrand. Shear Bond Strength of Self-Etching Adhesive Systems to Er:YAG Laser-Prepared Dentine with and without Pulpal Pressure Simulation. Photomedicine and Laser Surgery, 2008, 26 (6), pp.Pages 579583. 10.1089/pho.2007.2189 . hal-00508394

\section{HAL Id: hal-00508394}

https: / hal-mines-paristech.archives-ouvertes.fr/hal-00508394

Submitted on 16 Mar 2011

HAL is a multi-disciplinary open access archive for the deposit and dissemination of scientific research documents, whether they are published or not. The documents may come from teaching and research institutions in France or abroad, or from public or private research centers.
L'archive ouverte pluridisciplinaire HAL, est destinée au dépôt et à la diffusion de documents scientifiques de niveau recherche, publiés ou non, émanant des établissements d'enseignement et de recherche français ou étrangers, des laboratoires publics ou privés. 


\title{
Shear Bond Strength of Self-Etching Adhesive Systems to Er:YAG Laser-Prepared Dentine with and without Pulpal Pressure Simulation
}

\author{
Nathalie Brulat, D.D.S., Ph.D., ${ }^{1}$ Eric Leforestier, D.D.S., Ph.D., ${ }^{1}$ Jean-Paul Rocca, D.D.S., Ph.D., ${ }^{1}$ \\ Evelyne Darquet-Cerretti, Ph.D., ${ }^{2}$ and Marie-France Bertrand, D.D.S., Ph.D. ${ }^{1}$
}

\begin{abstract}
Objective: This study was conducted to study the role of pulpal pressure on the shear bond strength of composite resin bonded to Er:YAG laser-prepared or bur-prepared dentine surfaces using a self-etching adhesive system. Materials and Methods: The occlusal surfaces of 80 human third molars were ground flat to expose the dentine. The dentine was prepared using either a carbide bur or an Er:YAG laser at $350 \mathrm{~mJ} / \mathrm{pulse}$ and 10 $\mathrm{Hz}$ (fluence $44.5 \mathrm{~J} / \mathrm{cm}^{2}$ ). Clearfil SE Bond was then applied with or without pressure. Rods of composite resin were bonded to dentine surfaces and shear bond tests were carried out. Results: When the Clearfil SE Bond was used without pressure, the difference between the shear bond strength values of bur-prepared and laserprepared dentine surfaces was significant. When the Clearfil SE Bond was used with pressure, the difference of shear bond strength values was not significant between the two types of surface preparation. Conclusion: The absence of smear layer formation during the preparation of the dentine by the Er:YAG laser did not improve the adhesion values of self-etching adhesive systems.
\end{abstract}

\section{Introduction}

E RBIUM:YTTRIUM-ALUMINUM-GARNET (Er:YAG) laser irradiation was first used 10 years ago as a new method for preparing dental hard tissues. This technique is proposed to replace the high-speed air turbine and low-speed drills. The Er:YAG laser emits energy in the mid-infrared region (2.94 $\mu \mathrm{m})$ that falls in an area of the spectrum where dental tissues have absorption peaks (high absorption by water and hydroxyapatite). ${ }^{1}$ This laser was used for enamel/dentine surface treatment and removal of carious lesions in an effort to advance minimally-invasive dentistry. ${ }^{2}$ To protect the pulp from dangerous overheating, a cooling medium (a mixed water and air spray) is used. ${ }^{1}$ The Er:YAG laser is a good way to safely remove hard dental tissues. After preparation with this technique the irradiated dentine acquires microscopically irregular surfaces and open dentinal tubules, without a smear layer. ${ }^{3}$ Studies have been performed on the bond strength of composite resin to Er:YAG laser-irradiated dentine. ${ }^{4}$ The results have shown that bond strength increases when the surface is acid etched before bonding.
Dentinal moisture, as well as regional structural differences, are important factors that affect the bond strength to dentine.

Thus pulpal pressure may influence the degree of intrinsic wetness of the dentine surface. ${ }^{5}$ With new self-etching adhesive systems, the dentinal smear layer is no longer completely eliminated, but is instead treated like a substrate. ${ }^{6}$ One-step self-etching adhesive systems, also called "all-inone" systems, contain an etching agent, a primer, and an adhesive in a single agent. The adhesion values to irradiated dentine surfaces with these new materials are still being analyzed. ${ }^{7}$ The adhesive we used in this study (Clearfil SE Bond) is a self-etching adhesive treatment packaged in two bottles: one contains the acid primer and the other contains the adhesive.

The purpose of this study was to measure the bond strength of composite resin to Er:YAG-prepared dentine using self-etching with or without pulpal pressure versus the bond strength to bur-prepared dentine. The presence of resin tags with or without pressure was also assessed to study their influence on shear bond strength.

${ }^{1}$ Laboratory of Laser Technology and Oral Environment, University of Nice-Sophia Antipolis, and ${ }^{2}$ Center for Material Forming, Mines Paris Tech, Sophia Antipolis, Nice, France. 


\section{Material and Methods}

Eighty freshly extracted caries-free human third molars were used for this in vitro study. They were hand scaled, cleaned, and stored in distilled water at $4^{\circ} \mathrm{C}$ for up to 1 mo. These teeth were then randomly divided into two groups of 40 teeth each. Collection of these samples conformed to a protocol that satisfied the ethical standards set forth by the Centre Hospitalier Universitaire de Nice. The teeth were extracted for periodontal reasons and were obtained from patients who orally consented to their use for research purposes.

In the first group, the apices were cut to $3 \mathrm{~mm}$ and the pulp tissue was removed. A cylindrical hole was made in the pulp cavity, and a metal tube was inserted into the hole and glued in place.

The teeth in both groups were embedded in epoxide resin (Epoxycure resin; Buehler Ltd., Lake Bluff, IL, USA). Flat dentine surfaces were obtained by transverse sectioning of the crowns at a distance of $4 \mathrm{~mm}$ from the occlusal surface, using a slowly rotating diamond blade under running water (Isomet 2000; Buehler Ltd.).

The dentinal surfaces of 40 teeth in the first group (20 with the metal tube and 20 without; bur-prepared group) were prepared using a tungsten carbide bur (ref. H1.204.014; Komet, Gebr Brasseler, Lemgo, Germany) at high-speed under water cooling. The dentinal surfaces of 40 teeth (20 with the metal tube and 20 without; laser-prepared group) in the second group were prepared using an Er:YAG laser (Key $3^{\mathrm{TM}}$; Kavo Dental, Biberach, Germany), with an output energy of $350 \mathrm{~mJ}$ per pulse and a frequency of $10 \mathrm{~Hz}$. The laser beam was delivered perpendicularly to the dentinal surface, with a mirror handpiece (2060 ${ }^{\mathrm{TM}}$; Kavo Dental) at a distance of $12 \mathrm{~mm}$. This distance was manually maintained in the same manner used in clinical practice. The spot diameter was $0.8 \mathrm{~mm}$ (fluence of $44.5 \mathrm{~J} / \mathrm{cm}^{2}$ ) and the time of irradiation was $15 \mathrm{sec}$. Cooling was achieved using an air/water spray. More details about the irradiation parameters can be found in references 8 and 9 . After preparation all the teeth were air dried.
The intradentinal pressure is the pressure on the dentine imposed by the pulpal parenchyma. To simulate this pressure each tooth with a metal tube was connected by a flexible silicone hose to a water bottle placed vertically $35 \mathrm{~cm}$ above the sample. The system was evacuated with a vacuum pump and filled with bubble-free water (Fig. 1). The pulpal pressure device we used was based on an original idea proposed by Krejci et al. ${ }^{10}$ Pulpal pressure is equivalent to $14 \mathrm{~cm}$ of water, and the intradentinal pressure is equivalent to $34 \mathrm{~cm}$ of water.

The same self-etching adhesive system (Clearfil SE Bond ${ }^{\mathrm{TM}}$; two bottles, batch \#41284; Kuraray, Kurashiki City, Japan) was used for all teeth, and the teeth were prepared according to the manufacturer's recommendations. The selfetching primer was first applied to the dentinal surface. After a 20-sec resting period, the samples were briefly air dried. The adhesive resin was then applied, briefly air dried, and photopolymerized for $10 \mathrm{sec}$ (Astralis 5 ${ }^{\mathrm{TM}}$; Vivadent, Schaan, Liechtenstein).

A plastic ring (internal diameter of $5 \mathrm{~mm}$ ) was placed on the dentinal surface of each tooth. A microhybrid composite resin (Spectrum TPH ${ }^{\mathrm{TM}}$, batch \#0012000850; DetreyDentsply, Konstanz, Germany) was applied in three 1-mm layers, and each layer was photopolymerized for $40 \mathrm{sec}$ (Astralis $5^{\mathrm{TM}}$, Vivadent), reaching $3 \mathrm{~mm}$ in total height. The plastic ring was then removed and excess adhesive was removed using a polishing disc (Sof-Lex ${ }^{\mathrm{TM}}$; $3 \mathrm{M}$ Espe, St. Paul, MN, USA). The base of each sample was checked using an optical microscope (Olympus VMZ, Tokyo, Japan). The samples were then stored in distilled water at $37^{\circ} \mathrm{C}$ for $48 \mathrm{~h}$.

The shear bond strength measurements were carried out using a universal tensile testing machine (Erischen, Wuppertal, Germany) provided with a $2-\mathrm{kN}$ sensor, at a velocity of $0.02 \mathrm{~mm} / \mathrm{sec}^{-1}$. The fractured samples (dentine surfaces and composite resin rods) were placed on aluminum stubs and dried for $7 \mathrm{~d}$ in a drying oven at $37^{\circ} \mathrm{C}$. They were then gold sputter-coated (JFC-1100E ion sputter; JEOL, Tokyo, Japan). The coated specimens were examined under a scanning electron microscope (SEM) (JSM-5310LV; JEOL) to de-

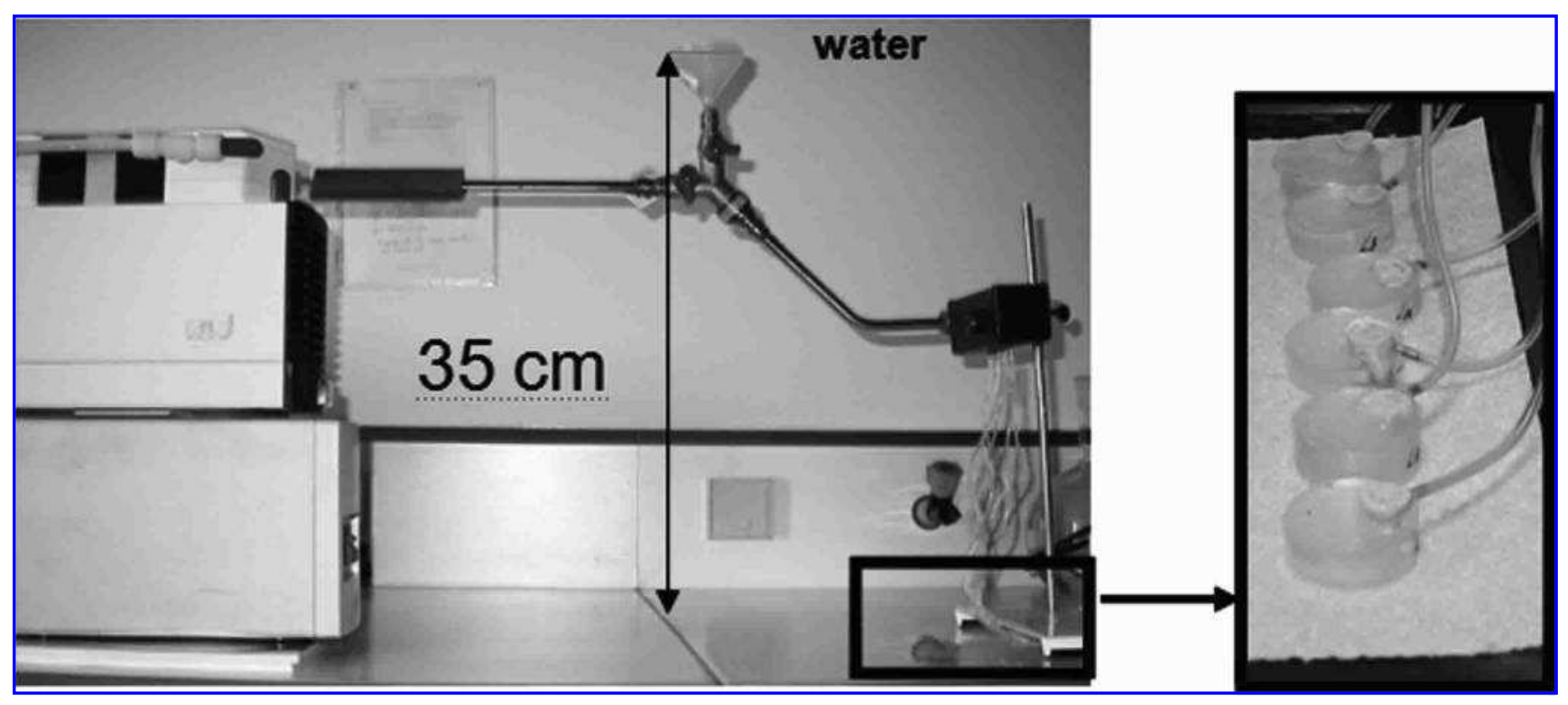

FIG. 1. Photograph of the pulpal pressure device used in this study. 
Table 1. Shear Bond Strength Values (MPa)

\begin{tabular}{|c|c|c|c|c|}
\hline & \multicolumn{2}{|c|}{$\begin{array}{c}\text { Clearfil } \\
\text { SE Bond } \\
\text { without pressure }\end{array}$} & \multicolumn{2}{|c|}{$\begin{array}{c}\text { Clearfil } \\
\text { SE Bond } \\
\text { with pressure }\end{array}$} \\
\hline & Bur & Er:YAG & Bur & $E r: Y A G$ \\
\hline Mean & $13.87^{\mathrm{a}}$ & $9.62^{b}$ & $7.99^{\mathrm{b}}$ & $9.52^{b}$ \\
\hline Standard deviation & 5.25 & 3.28 & 2.77 & 4.38 \\
\hline
\end{tabular}

Different letters indicate statistically significant differences.

termine the types of failure present, which were classified as cohesive, adhesive, or mixed (both cohesive and adhesive failure zones present on the same fractured surface). These results have been detailed in reference 11 (in press).

Statistical analysis of the results was performed using the non-parametric Kruskal-Wallis test and the Mann-Whitney $\mathrm{U}$ test for independent samples, as well as Fisher's exact test. Statistical significance was set at $p<0.05$

In the second part of this study the SEM observations were performed in an environmental mode. (The SEM environmental node is dedicated to the observation of samples without metalization.) Eight dentine surfaces were divided into two groups of four teeth each, one group received pressure and the other group did not.

The surface of each tooth was divided into two parts: one was prepared with a bur and the other was prepared using the ER:YAG laser. The bonding protocol was the same except as that described above, except that the composite thickness was $1 \mathrm{~mm}$ and they were photopolymerized under glass pressure. Each specimen was divided into three longitudinal sections: two sections were sputter coated and examined with the SEM, and the last one was examined using the SEM in an environmental mode.

\section{Results}

\section{Comparing shear bond strengths}

Shearing experiments ${ }^{11}$ were performed on the 80 teeth prepared as described above. Mean shear bond strength measurements and standard deviations are presented in Table 1.

Without pressure, the shear bond strengths of the Er:YAG laser-prepared surfaces were lower than those seen on burprepared surfaces $(p=0.0053)$. With pressure, the shear bond strengths of the bur-prepared surfaces and the laserprepared surfaces were not statistically significantly different $(p=0.3867)$. The shear bond strengths obtained for the bur-prepared surfaces were statistically significantly weaker with pressure than without $(p=0.0003)$. The shear bond strengths obtained for the laser-prepared surfaces were nearly the same both with and without pressure $(p=1)$.

\section{Comparing resin tags}

Without pressure, long resin tags (around $10 \mu \mathrm{m}$ ) were seen on the surfaces prepared using the bur (Fig. 2A). On the surfaces prepared using the laser these tags were more numerous, longer, were bunched together (Fig. 2B).

With pressure, the resin tags were still numerous, but they were shorter (around $1 \hat{\mathrm{Em}}$ ) on surfaces prepared using the bur (Fig. 3A). On surfaces prepared using the laser, we observed fewer resin tags and their diameters are smaller (Fig. 3B).

\section{Discussion}

With the use of the intradentinal pressure device, the amount of moisture in the substrate was maximal. Actual clinical results would likely fall between the two sets of results obtained with and without pressure, since in vivo plasma proteins aggregate with the primer. ${ }^{12}$ This aggregation causes a decrease in the diameters of the tubules, and thus a decrease in the amount of surface humidity present.

\section{Shear bond strength}

As early as 1991, Mitchen and Gronas proposed that pressure decreases adhesive bonding strength, particularly in the absence of a smear layer. ${ }^{13}$ Our results show that the smear layer does not appear to affect bonding strength. Indeed, the bonding values obtained with pressure on surfaces prepared with the bur (in the presence of a smear layer) and with the
A

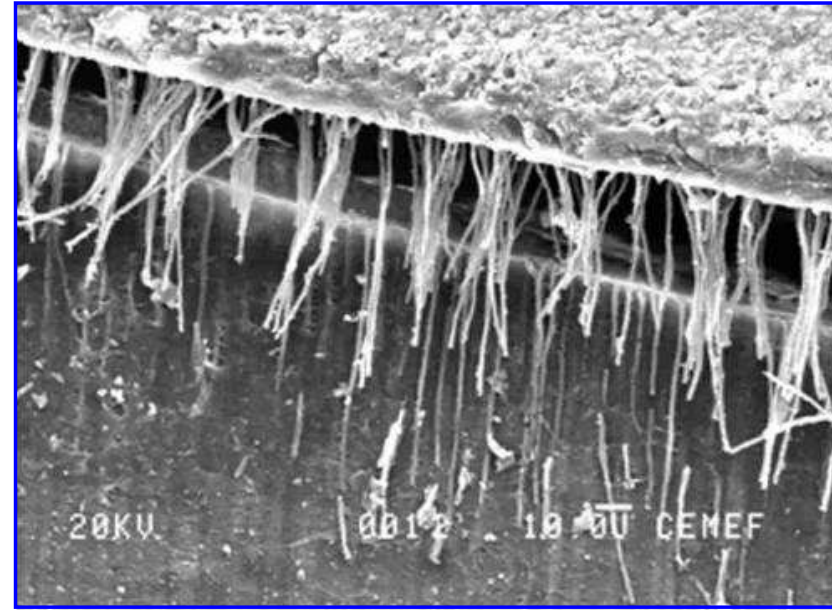

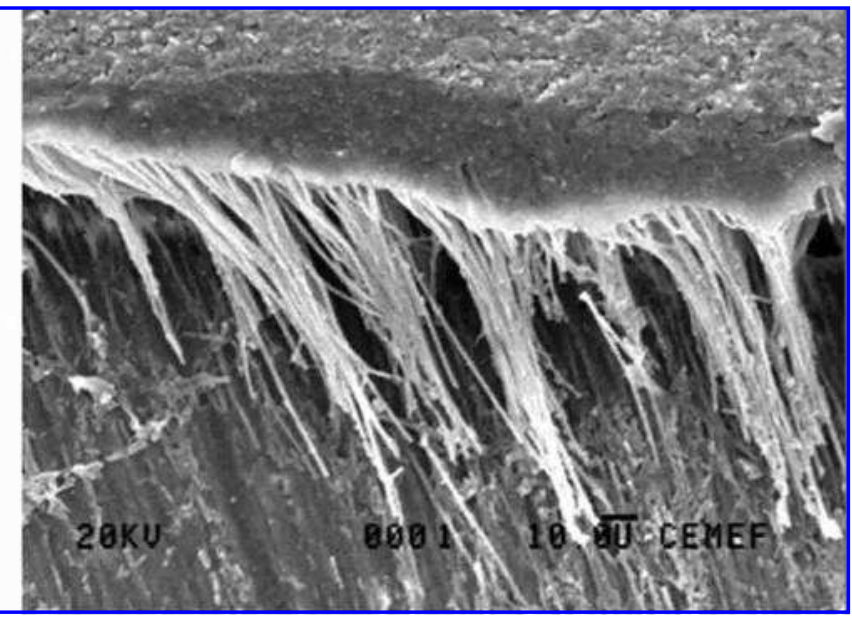

FIG. 2. Resin tags on surfaces prepared with the bur (A) or the laser (B) without intradentinal pressure. 


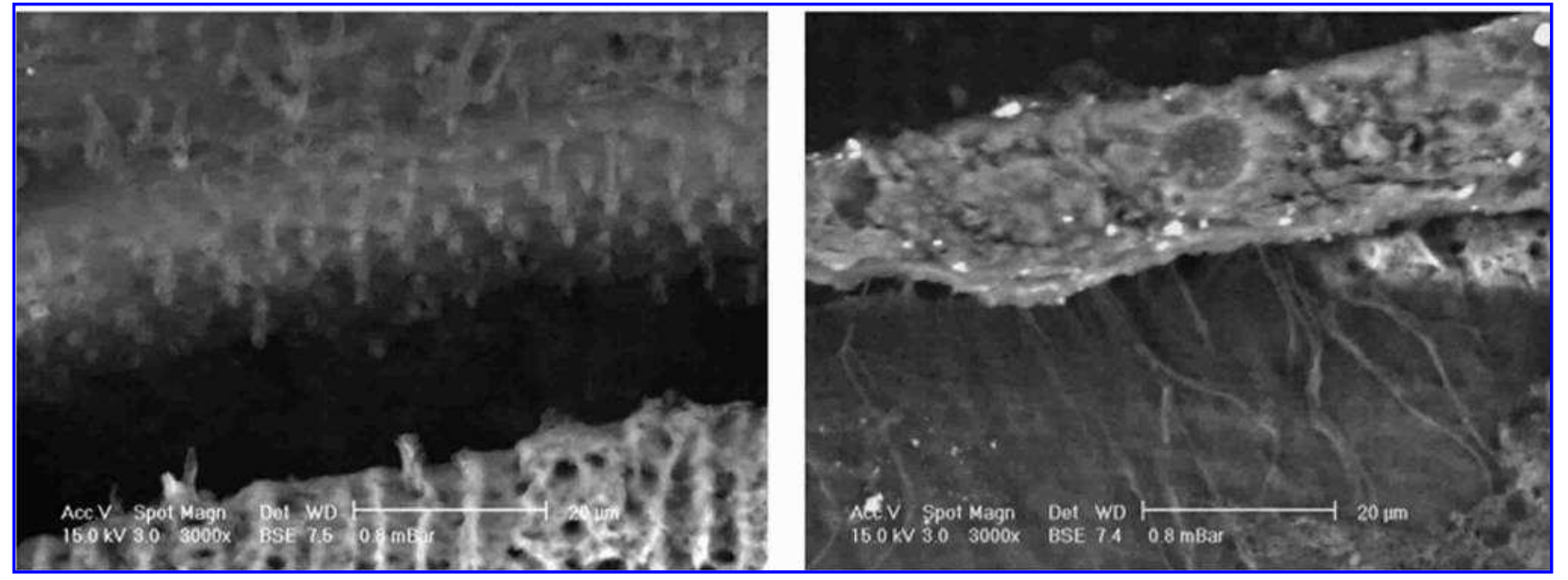

FIG. 3. Resin tags on surfaces prepared with the bur (A) or the laser (B) with intradentinal pressure.

laser (without a smear layer) were nearly the same. When we used the self-etching adhesive system on bur-prepared surfaces, the bond values decreased when intradentinal pressure was used during bonding.

The results we obtained from surfaces prepared with the bur along with intradentinal pressure are in good agreement with other studies in the literature. Most adhesives have lower bonding strength when used with pulpal or intradentinal pressure. In the work done by Nystrom et al. in 1998 using Scotch Bond MP, they found that even if the primer was hydrophilic, it did not penetrate into the demineralized dentine. ${ }^{14}$ In 2000, Zeng et al. tested the Xeno III and the Dyract AP systems. They concluded that when under pressure, the primer does not penetrate properly because the HEMA was diluted before it was completely polymerized. ${ }^{15}$ Pioch and Staehle tested the Syntac, Prime and Bond, and Gluma bonding systems. Their hypothesis was that the pressure would prevent the adhesive solvent from volatilizing. ${ }^{5}$ Finally, Sengun et al. in 2003 tested the CLB2V system, and its composition is similar to that of the system we tested, Clearfil SE. The waiting periods before polymerization are slightly different for the two systems (30 sec for CLB2V and $20 \mathrm{sec}$ for Clearfil SE). They also postulated that dilution of the HEMA was the reason for the decrease in bond strength seen when applied under pressure. ${ }^{16}$

\section{Resin tags}

Without pressure the Clearfil SE tags were more numerous on the surfaces prepared with the laser. One hypothesis for this is that the smear layer on the bur-prepared surfaces slowed the adhesive's penetration. Inversely, on the laserprepared surfaces the tubules were wider, which made adhesive penetration easier.

With pressure, there were fewer tags with both types of surface preparation. One reason for this may be that the adhesive's hydrophilicity and its ability to penetrate tubules plays an important role when bonding to a dentine surface under intrapulpal pressure.

We found resin tags on bur-prepared surfaces both with and without intrapulpal pressure; however, the tags were extremely short when bonded under pressure. This may be one of the reasons why bond values are lower for bur-prepared surfaces under pressure.

Concerning surfaces prepared using the laser, the absence of a smear layer enables the adhesive to bond to a cleaner surface. Thus the resin tags in those samples did not affect bond strength.

\section{Conclusion}

Here we compared the shear bond strength of a self-etching adhesive (Clearfil SE Bond) to surfaces prepared using an Er:YAG laser or a bur. Intrapulpal pressure was simulated to analyze its influence on shear bond strength. Shear bond strength values are clearly lower for bur-prepared surfaces when under intrapulpal pressure. Inversely, intrapulpal pressure did not significantly affect shear bond strength to laser-prepared surfaces. Intradentinal pressure also reduced the numbers of resin tags seen, but this did not significantly affect bond strength values to dentine prepared using the laser. The resin tags and the smear layer may play a role in the differences we found in our testing.

\section{Disclosure Statement}

No conflicting financial interests exist.

\section{References}

1. Hibst, R., and Keller, U. (1989). Experimental studies of the application of the Er:YAG laser on dental hard substances: I. Measurement of the ablation rate. Lasers Surg. Med. 9, 345-351.

2. Freitas, P.M., Navarro, R.S., Barros, J.A., and Eduardo, P. (2007). The use of Er:YAG laser for cavity preparation: An SEM evaluation. Microsc. Res. Tech. 70, 803-808.

3. Corona, S.A., de Souza, A.E., Chinelatti, M.A., Borsatto, M.C., Pecora, J.D., and Palma-Dibb, R.G. (2007). Effect of energy and pulse repetition rate of Er:YAG laser on dentin ablation ability and morphological analysis of the laser-irradiated substrate. Photomed. Laser Surg. 25, 26-33.

4. Bertrand, M.F. (2002). Préparations cavitaires au laser Er:YAG et collage d'une résine composite. Doctoral thesis in odontology, Université de Nice-Sophia Antipolis, Nice, France. 
5. Pioch, T., and Staehle, H.J. (2001). Effect of intrapulpal pressure simulation in vitro on shear bond strengths and hybrid layer formation. Am. J. Dent. 14, 319-323.

6. Kaaden, C., Powers, J.M., Friedl, K.H., and Schmalz, G. (2002). Bond strength of self-etching adhesives to dental hard tissues. Clin. Oral Investig. 6, 155-160.

7. Ramos, R.P., Chimello, D.T., Chinelatti, M.A., Nonaka, T., Pecora, J.D., and Palma Dibb, R.G. (2002). Effect of Er:YAG laser on bond strength to dentin of a self-etching primer and two single-bottle adhesive systems. Lasers Surg. Med. 31, 164-170.

8. Bertrand, M.F., Semez, G.F., Leforestier, E., Muller-Bolla, M., Nammour, S., and Rocca, J.P. (2006). Er:YAG laser cavity preparation and composite resin bonding with a single-component adhesive system: relationship between shear bond strength and microleakage. Lasers Surg. Med. 38, 615-623.

9. Brulat, N., Rocca, J.P., Leforestier, E., Darque-Ceretti, E., Nammour, S., and Bertrand, M.F. (2007). Wettability and surface energy comparison between dentin surface prepared with bur and Er:YAG laser. World Federation for Lasers in Dentistry, European Division, First Meeting (Nice, France). Lasers Med. Sci. 22, 285-315.

10. Krejci, I., Hausler, T., Sagesser D., and Lutz, F. (1994). New adhesives in class $\mathrm{V}$ restorations under combined load and simulated dentinal fluid. Dent. Mater. 10, 331-335.

11. Brulat, N., Rocca, J.P., Leforestier, E., Fiorucci, G., Nammour, S., and Bertrand, M.F. (accepted for publication). Shear bond strength of self-etching adhesive systems to Er:YAG laser prepared dentin. Lasers Med. Sci.
12. Nikaido, T., Burrow, M.F., Tagami, J., and Takatsu, T. (1995). Effect of pulpal pressure on adhesion of resin composite to dentin: bovine serum versus saline. Quintessence Int. 26, 221-226.

13. Mitchem, J.C., and Gronas, D.G. (1991). Adhesion to dentin with and without smear layer under varying degrees of wetness. J. Prosthet. Dent. 66, 619-622.

14. Nystrom, G.P., Holtan, J.R., Phelps, R.A., Becker, W.S., and Anderson, T.B. (1998). Temperature and humidity effects on bond strength of a dentinal adhesive. Oper. Dent. 23, 138-143.

15. Zeng, L., Pereira, P.N.R., Somphone, P., Nikaido T., and Tagami, J. (2000). Effect of hydrostatic pressure on regional bond strengths of compomers to dentine. J. Dent. 28, 501-508.

16. Sengun, A., Ozturk, B., and Ozer, F. (2003). The effect of simulated intrapulpal pressure on bond strength to enamel and dentine. J. Oral Rehabil. 30, 550-555.

Address reprint requests to: Nathalie Brulat, D.D.S., Ph.D. Laboratory of Laser Technology and Oral Environment University of Nice-Sophia Antipolis Pile Universitaire St Jean d'Angély 24 Avenue des Diables Bleus Nice, France 06357

E-mail: nathalie.brulat@unice.fr 